ISSN 2077-0472

www.mdpi.com/journal/agriculture

Article

\title{
Pollen Sterility-A Promising Approach to Gene Confinement and Breeding for Genetically Modified Bioenergy Crops
}

\author{
Joel P. Hague ${ }^{1}$, Stephen L. Dellaporta ${ }^{2}$, Maria A. Moreno ${ }^{2}$, Chip Longo ${ }^{1}$, Kimberly Nelson ${ }^{1}$ \\ and Albert P. Kausch ${ }^{1, *}$ \\ 1 Department of Cell and Molecular Biology, University of Rhode Island, West Kingston, RI 02892, \\ USA; E-Mails: joel.hague@gmail.com (J.P.H.); chipperdoo@msn.com (C.L.); \\ kimberlynelson@mail.uri.edu (K.N.) \\ 2 Department of Molecular Cellular and Developmental Biology, Yale University, New Haven, \\ CT 06520, USA; E-Mails: stephen.dellaporta@yale.edu (S.L.D.); \\ mariangelamorano@gmail.com (M.A.M.) \\ * Author to whom correspondence should be addressed; E-Mail: akausch@etal.uri.edu; \\ Tel.: +1-401-874-7121; Fax: +1-401-874-7124.
}

Received: 1 August 2012; in revised form: 10 September 2012 / Accepted: 18 September 2012 / Published: 16 October 2012

\begin{abstract}
Advanced genetic and biotechnology tools will be required to realize the full potential of food and bioenergy crops. Given current regulatory concerns, many transgenic traits might never be deregulated for commercial release without a robust gene confinement strategy in place. The potential for transgene flow from genetically modified (GM) crops is widely known. Pollen-mediated transfer is a major component of gene flow in flowering plants and therefore a potential avenue for the escape of transgenes from GM crops. One approach for preventing and/or mitigating transgene flow is the production of trait linked pollen sterility. To evaluate the feasibility of generating pollen sterility lines for gene confinement and breeding purposes we tested the utility of a promoter (Zm13Pro) from a maize pollen-specific gene $(\mathrm{Zml3})$ for driving expression of the reporter gene GUS and the cytotoxic gene barnase in transgenic rice (Oryza sativa ssp. Japonica cv. Nipponbare) as a monocot proxy for bioenergy grasses. This study demonstrates that the $Z m 13$ promoter can drive pollen-specific expression in stably transformed rice and may be useful for gametophytic transgene confinement and breeding strategies by pollen sterility in food and bioenergy crops.
\end{abstract}


Keywords: bioenergy; gene confinement; GM crops; transgenic plants; pollen sterility; regulatory concerns; agricultural regulation; environmental regulation; gametophyte; Oryza sativa

\section{Introduction}

The need to improve agricultural production of food and bioenergy crops has been considered by some to be a "moral imperative" [1]. To fully realize the potential of bioenergy, the power of advanced genetic and biotechnology tools need to be brought to bear on bioenergy crops [2,3]. Technologies such as transgenics, genomics, bioinformatics, hybrid plant development, advanced tissue culture, marker assisted breeding, and zinc finger nucleases (ZFNs) are just a few of the technologies that promise increased yield, processability, and regional adaptation of biofuel crops $[4,5]$. Traits that are targets for improvement of biofuels crops include herbicide-tolerance, pest-, drought-, cold- and salt-tolerance, nutrient use efficiency, increased vegetative biomass, production of biopolymers, altered cell wall composition and improved processing and end-use characteristics. Although there is an absence of serious documented risks among commercially-grown transgenic crops [6,7], commercial-scale production of certain combinations of transgenic traits and crops could potentially lead to undesirable environmental and agricultural consequences. This is because many of the traits that are beneficial to the commercial production of perennial plants potentially impact plant fitness and the ability of the plants to compete for resources [6,8]. Confinement of transgenes is thus an obvious regulatory and biosafety objective for the release and commercialization of transgenic bioenergy feedstocks $[9,10]$ as the development of fertile reproductive structures in genetically modified perennial plants will result in undesirable gene flow to non-transgenic and wild plants $[9,11-16]$. Hence, the control of gene flow is widely understood as a major obstacle to genetic improvement of perennial plants.

Given current regulatory concerns, many useful transgenic traits might never be realized without a practical system for transgene confinement (TC). Therefore, TC has important regulatory, economic, environmental and biosafety implications for the release and commercialization of transgenic bioenergy feedstocks. Various TC strategies have been devised based on hybrid plant systems $[2,9,11,17]$. The methods for transgenic hybrid plant gene confinement that have been developed so far include seed-based gene confinement, the gene deletor system, and various total sterility concepts. One of the best known is the GeneSafe Technology, known more commonly as "Terminator" [18-20]. This strategy uses an inducible site specific recombinase system (Cre/lox) to produce seed that will not germinate. The so-called Gene Deletor System [17] can be understood as a modification and elaboration of the GeneSafe Technology approach and as another example of a hybrid plant system that could be potentially applied for gene confinement in perennial plants. Initially designed as a system to remove transgenic DNA fragments from pollen and seed [17], Gene Deletor also uses recombinases to cause excision of designed sequences to eliminate their transmission to the progeny. While touted to increase efficiency of sequence excision, this system also suffers from the inherent inefficiency of recombinase-based systems in an $\mathrm{F}_{1}$ generation which makes them impractical 
for commercial hybrid cross applications [21-23]. Therefore, while recombinase-mediated excision technologies are practical for removal of specific DNA insertions, the inability to use these systems for gene confinement in hybrid plant systems is evident by the lack of reports in peer reviewed and patent literature or practical application in commercial crops.

Although transgene escape can occur through seed scatter and vegetative propagation, the most likely mode of transmission is via pollen $[13,24,25]$. The potential for transgene flow from GM crops has been made clear by a number of previous reports [12,13,15,24,26-31]. One tactic for preventing and/or mitigating transgene flow is the production of nuclear male-sterile transgenic plants incapable of developing fertile pollen carrying transgenes [2]. For instance, physical linkage of a gene encoding a cytotoxic molecule (such as barnase) to a tissue or developmentally-specific promoter could be used to produce male-sterile transgenic plants [2,11]. This type of approach has been well established as an effective strategy for production of male sterility in plants [32-35]. Furthermore, hybrid plants in many crop species have historically contributed to increased yields throughout the world. Management of pollen development and release is critical to hybrid breeding schemes utilizing inbred lines for the production of hybrid seed [36,37]. However, in co-sexual plants where the female and male reproductive structures are present in the same flower (e.g., rice) it is difficult to produce commercial quantities of hybrid seed [38]. Manual emasculation (i.e., detasseling) is used in commercial hybrid maize production and in some vegetables (e.g., tomato), however, the extension of such practices to crops with small bisexual flowers (e.g., rice, switchgrass, rye) is limited by cost and practicality [38]. Therefore, in addition to gene confinement, it would be of great interest to plant breeders to develop additional pollination control techniques [39].

Pollen-specific genes from maize $[40,41]$ and tomato $[42,43]$ have been cloned and their promoters extensively characterized [44-51]. Deletion analysis of each of these promoters has identified sequence elements responsible for pollen-specificity as well expression modulation [46-49]. Promoter fragments of the maize pollen-specific gene $Z m 13$ fused to gus $A$ were shown to direct pollen-specific GUS activity in transient expression assays of Tradescantia and maize utilizing microprojectile bombardment [46-49] as well as in stably-transformed Arabidopsis and tobacco. Thus, the $5^{\prime}$ regulatory elements of the $Z m 13$ gene serve as an obvious sequence of interest for creating a TC system in transgenic plants.

It is the development of TC/hybrid technology using a maize pollen specific promoter (Zm13Pro) that is the purpose of this investigation. Three genetic transformation constructs were used in this study to analyze the expression characteristics of the Zm13Pro linked to a reporter gene, to determine co-transformation and expression of a linked selectable marker gene cassette in genetically engineered rice serving as a monocot proxy for bioenergy crops, and examine the potential applicability of Zm13Pro in gametophytic transgene confinement and hybrid breeding strategies.

\section{Results and Discussion}

To be useful as a tool in transgene confinement and/or breeding strategies, the $Z m 13$ promoter must be co-expressed with additional trait gene(s) of interest, stably inherited as a single Mendelian trait, and pollen specific without deleterious spurious expression. To test the utility of Zm13Pro, we constructed three transformation vectors (Figure 1). The first (pOsUbiPro::GUS) uses a ubiquitin 
promoter [52] from rice (OsUbiPro) driving expression of the gusA reporter gene; this is linked to $h p t$ (hygromycin phosphotransferase) as a plant selectable marker for hygromycin B resistance (Figure 1A) driven by the double enhancer version of the Cauliflower Mosaic Virus 35S promoter (D35S). The second (pZm13Pro::GUS) uses the Zm13 promoter (Zm13Pro) linked to gusA (Figure 1B); this was designed to test tissue and developmental specificity and also used the D35S::hpt::35SA cassette as a selectable marker. The third (pZm13Pro::barnase) was intended to test whether the Zm13Pro element is capable of conferring pollen sterility (Figure 1C). This construct is the same as the second, except $h p t$ was replaced by bar (phosphinothricin acetyl transferase), which confers tolerance to glufosinate ammonium herbicides, and gusA was replaced by the ribonuclease barnase (Zm13Pro::barnase).

Figure 1. Diagrammatic representation of the test constructs. (A) For constitutive expression and as a positive GUS control, a rice ubiquitin promoter (OsUbiPro) drives expression of a gusA with a 35A 3' termination signal; this was linked to hpt (hygromycin phosphotransferase) driven by the double enhancer version of the Cauliflower Mosaic Virus 35S promoter (D35S) as a plant selectable marker for hygromycin B resistance; (B) The $Z m 13$ promoter driving the reporter gene gus A with a 35A $3^{\prime}$ termination signal was designed to test tissue and developmental specificity; (C) The Zm13 promoter driving the cytoxin barnase gene with a nos 3' termination signal linked to a D35S::bar::nos cassette as a selectable marker cassette conferring herbicide tolerance.

A. pOsUbiPro::GUSReporter Construct

- D35SPro $h p t \rightarrow 35 \mathrm{SA}$ OsUbiPro

B. pZm13Pro::GUS Reporter Construct

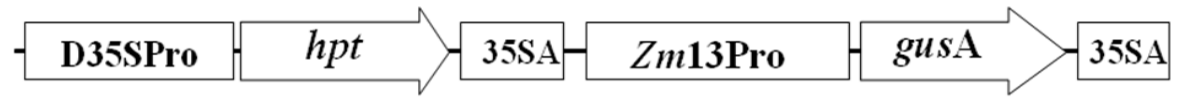

C. pZm13Pro::barnase Sterility Construct

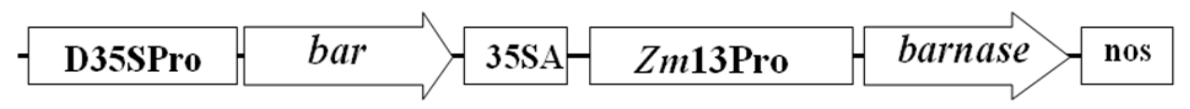

\subsection{Co-Expression of hpt and gusA in Transgenic Rice Embryogenic Callus}

Reporter gene expression was evaluated in embryogenic callus to determine whether Zm13Pro::barnase expression in callus may interfere with isolation of transgenic events. Embryogenic calli were induced from mature dehusked surface-sterile caryopses and co-cultivated with LBA4404 Agrobacterium containing each of the test constructs shown in Figure 1 independently. Constructs pOsUbiPro::GUS (A) and pZm13Pro::GUS (B) each carry an hpt (hygromycin phosphotransferase) plant selectable marker gene to confer hygromycin B resistance. Putatively transformed hygromycin resistant calli were identified after 8-10 weeks of growth on callus induction medium supplemented with $50 \mathrm{mg} \cdot \mathrm{L}^{-1}$ hygromycin B. Fifty-eight independent hygromycin B-resistant calli (events) were recovered via Agrobacterium-mediated transformation. The resistant calli were all embryogenic and 
grew normally with similar doubling times in comparison to non-transformed embryogenic rice callus maintained on the same medium sans hygromycin. After treatment with antibiotics to remove the Agrobacterium, all 58 hygromycin B-resistant calli were moved to regeneration medium, with 44 events regenerating to give rise to putatively transgenic plantlets. Ten regenerated plants (clones) from each of the 44 events were transplanted to pots and grown to maturity under greenhouse conditions. All plants appeared morphologically normal and matured to produce inflorescences.

Portions of resistant calli from each of the recovered transformed events (and nontransformed controls) were removed and histochemically stained for GUS activity (Figure 2). Five independent pOsUbiPro::GUS transgenic events were tested and exhibited uniform expression throughout all calli (Figure 2A). None of the nontransformed control calli showed any GUS activity (not shown). Thirteen of the pZm13Pro::GUS transgenic calli showed GUS activity with a mottled staining pattern of variable intensity (not shown), while the remaining 45 hygromycin resistant calli exhibited no visible GUS activity (Figure 2B).

Figure 2. GUS activity in undifferentiated embryogenic callus. GUS activity in embryogenic hygromycin resistant callus transformed with (A) pOsUbiPro::GUS and

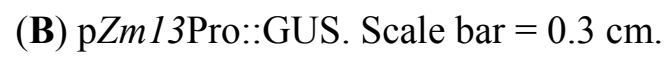
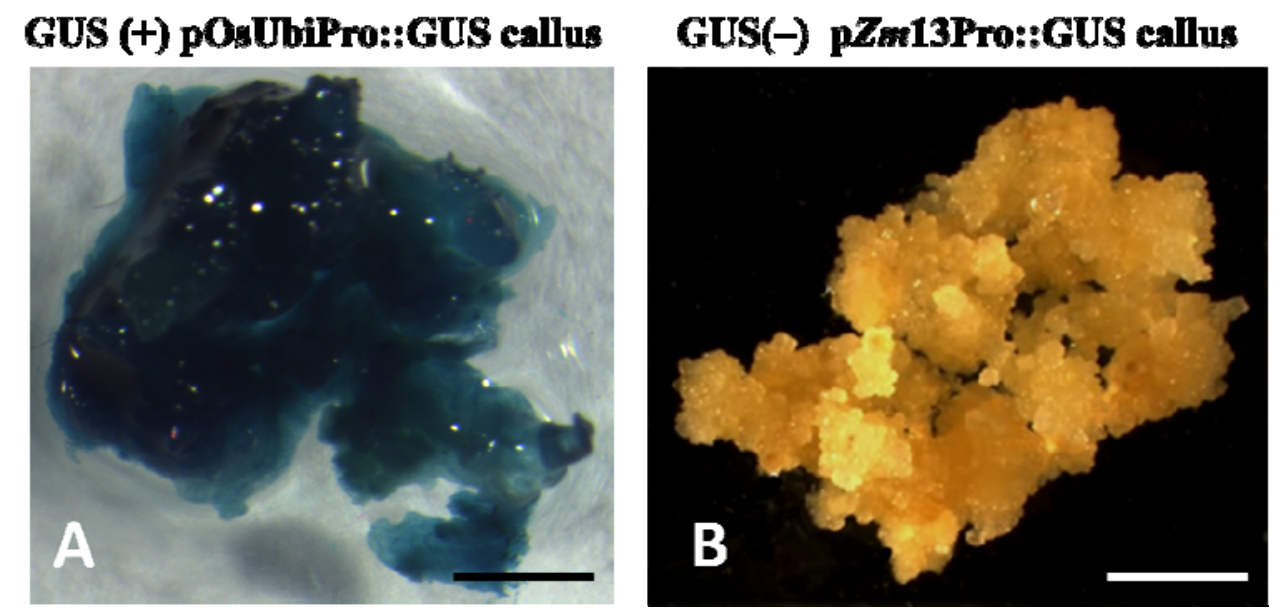

While some pZm13Pro::GUS events exhibited ectopic expression of gus $A$ in embryogenic callus, others did not. This could be due to a variety of reasons, including, as a result of position effects of the relative insertion of the transgenes, transgene copy number, undetermined developmental factors in embryogenic cultures, or alteration of the inserted transgene. If the pZm13Pro::barnase cassette were also expressed in a similar manner, it is likely that these events would not be recovered, lowering the apparent transformation efficiency with this construct. However, significant numbers of independent transgenic events lacking detectable GUS activity were recovered with pZm13Pro::GUS, indicating that pZm13Pro::barnase events could be also recovered. Also, it is apparent that the D35S::hpt::35SA cassette was both co-integrated and co-expressed resulting in the recovery of hygromycin resistant callus which either did or did not express the linked gusA. 


\subsection{Molecular Analysis of Transgenic Plants}

Molecular analysis was conducted on all pOsUbiPro::GUS and pZm13Pro::GUS transgenic events to confirm the presence of intact T-DNA insertions. After subculture and rooting on $\mathrm{R}_{\mathrm{II}}$ medium, $10 \mathrm{~T}_{0}$ plantlets from each putative transgenic event were transplanted to soil and maintained under greenhouse conditions. Prior to flowering, genomic DNA was isolated from each plantlet after the method of Chen and Dellaporta [53]. $\mathrm{T}_{0}$ plants were screened for the presence of the gusA and $h p t$ transgenes via PCR. The GUS transgenics were analyzed by PCR using primer pairs that internally amplify a 494 bp gusA fragment and a 362 bp hpt fragment, respectively. Using gusA-specific primers against positive control plasmid DNA(+) and wild-type cv Nipponbare DNA negative control(-), plants $31,69,227,344,625,680,717$, and 717 were PCR-positive for presence of the gusA transgene. These $\mathrm{T}_{0}$ plantlets show PCR products consistent with the expected $494 \mathrm{bp}$ (Figure 3). Verification of the presence of the $h p t$ transgene was accomplished via $h p t$-specific primers using the identical controls; the same $\mathrm{T}_{0}$ plants $(31,69,227,344,625,680,717$, and 718 , respectively) tested positive for the presence of the $h p t$ transgene as these $\mathrm{T}_{0}$ events yielded PCR products consistent with the expected 362 bp hpt product (Figure 4).

Figure 3. PCR screening of plantlets regenerated from hygromycin resistant $\mathrm{T}_{0}$ events using gusA-specific primers. (+) positive control, plasmid DNA; (-) negative control, wild-type cv. Nipponbare DNA. Plant identification numbers 31, 69, 227, 344, 625, 680, 717 , and 718 show PCR products consistent with the expected 494 bp control fragment. PCR products were separated on a $1.2 \%$ agarose gel.

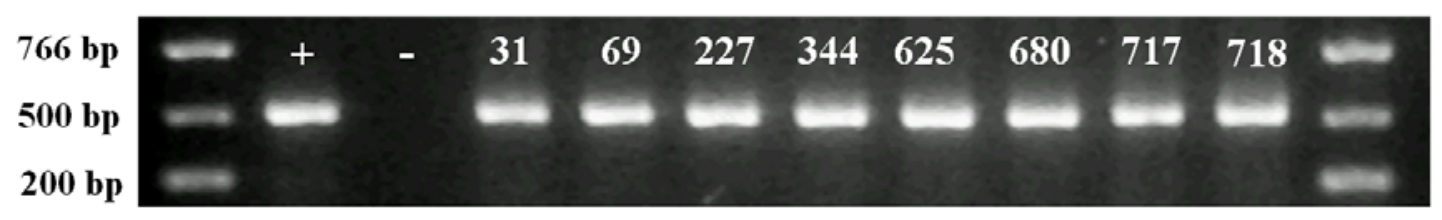

Figure 4. PCR screening of plantlets regenerated from hygromycin resistant $T_{0}$ events using hpt-specific primers. (+) positive control, plasmid DNA; (-) negative control, wild-type cv. Nipponbare DNA. Plant identification numbers 31, 69, 227, 344, 625, 680, 717 , and 718 show PCR products consistent with the expected $362 \mathrm{bp}$ control fragment. PCR products were separated on a $1.2 \%$ agarose gel.

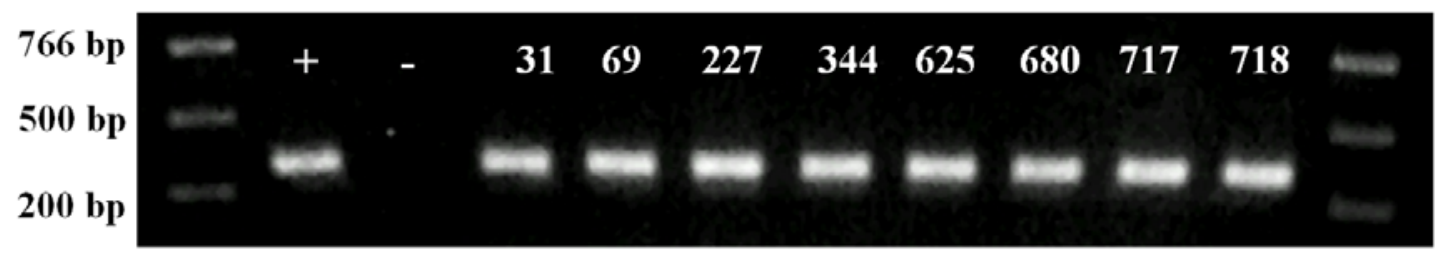

All $44 \mathrm{~T}_{0}$ plants which had been regenerated from hygromycin resistant calli tested positive for the gusA and $h p t$ transgenes, indicating that each regenerated transgenic event carried at least one intact copy of both the gusA and hpt transgene cassettes. Five plants from each selected transgenic event 
were chosen for out-crossing to wild-type cv. Nipponbare to generate a $\mathrm{T}_{1}$ population while the remaining five were used for histochemical analysis.

Genomic DNA from the $\mathrm{T}_{1}$ offspring of selected $\mathrm{T}_{0}$ events exhibiting pollen-specific gusA transgene expression was also collected as described above. Co-segregation of the gusA and hpt transgenes in a PCR screen of a representative $T_{1}$ line, 30-6 was examined using PCR (Figure 5). Progeny plant identification numbers $1,3,4,6,7,8$, and 9 show consistent co-segregation of the gusA gene and $h p t$ transgenes. All $\mathrm{T}_{1}$ lines were screened for the presence of the gusA and $h p t$ transgenes under PCR conditions identical to those employed in the screening of $\mathrm{T}_{0}$ events.

Figure 5. Co-segregation of the gusA and hpt transgenes in a PCR screen of a representative $\mathrm{T}_{1}$ line, 30-6. (+) positive control, plasmid DNA; (-) negative control, wild-type $O$. sativa cv. Nipponbare DNA. Progeny plant identification numbers 1, 3, 4, 6, 7,8 , and 9 are given above each lane. Products run on a $1.2 \%$ agarose gel.

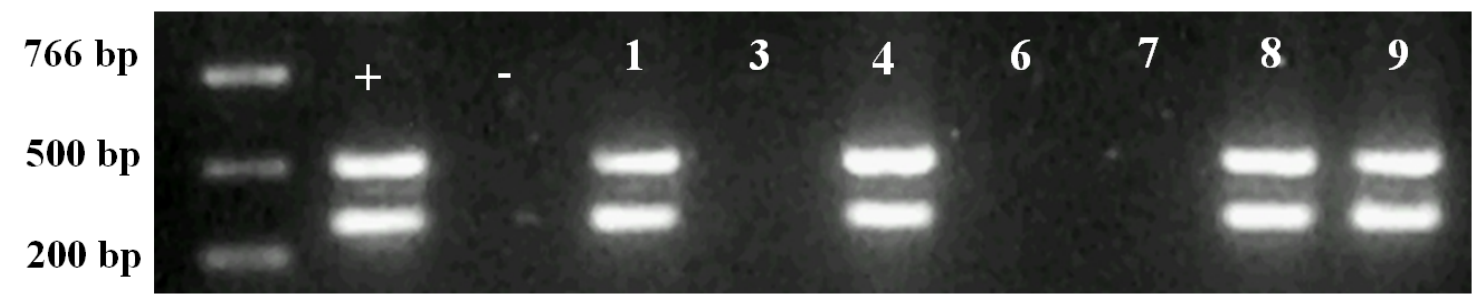

Southern blot analyses were conducted on $\mathrm{T}_{0}$ plants which tested PCR positive for the gus $A$ gene and $h p t$ transgenes (Figure 6). High molecular weight genomic DNA from transgenic plants expressing the GUS transgene was restricted with EcoRV and hybridized to a DIG-labeled hpt probe. DNA samples taken from individual plants regenerated from the same hygromycin resistant callus (i.e., clones) show identical banding patterns and indicate that this particular event carries multiple T-DNA insertions. DNA samples from individual GUS positive and hygromycin resistant plants that had been regenerated from independent hygromycin resistant calli (i.e., independent transformants), show individual bands indicating that some are likely single T-DNA insertion events. DNA from wild-type non-transformed $O$. sativa $\mathrm{cv}$ Nipponbare was used as a negative control and showed no hybridization to the DIG-labeled $h p t$ probe.

Each $\mathrm{T}_{1}$ line co-segregated for the presence of the gus $A$ and $h p t$ transgenes (except a single $\mathrm{T}_{1}$ line that did not exhibit segregation by expression for GUS activity in its pollen), indicating that the transgenes were integrated as single Mendelian loci into the host $\mathrm{T}_{0}$ genomes. All $\mathrm{T}_{1}$ offspring testing positive for the presence of the hpt and gusA transgenes exhibited GUS activity in pollen, excepting two $\mathrm{T}_{1}$ offspring of $\mathrm{T}_{0}$ event 344 ; these plants tested positive in the PCR screen, but lacked any visually detectable GUS activity in pollen, suggesting the possibility of silencing of the gusA transgene in those plants. The same five independent pOsUbiPro::GUS transgenic events discussed above were regenerated to $\mathrm{T}_{0}$ plants and tested positive by PCR for both the hpt and gusA genes (not shown). As with the $\mathrm{pZm13Pro::GUS} \mathrm{T}_{0}$ transgenics, five plants from each selected pOsUbiPro::GUS transgenic event were selfed to generate a $\mathrm{T}_{1}$ population and were subsequently used for histochemical analysis. All control $\mathrm{T}_{1}$ lines were screened for the presence of the gusA and hpt transgenes under PCR 
conditions identical to those employed in the screening of $\mathrm{T}_{0}$ events. None of the non-transformed control plants generated PCR bands for either transgene (not shown).

Figure 6. Southern blot analysis of $\mathrm{T}_{0}$ plants carrying the hpt transgene. Genomic DNA from transgenic plants expressing the GUS transgene was restricted with EcoRV and hybridized to a DIG-labeled hpt probe. DIG-labeled DNA molecular weight marker III is shown in lane M. In lanes 4-6, are samples from individual plants regenerated from the same hygromycin resistant callus showing identical banding patterns and indicating the plants are likely clones carrying multiple identical T-DNA insertions. In lanes 1-3, 7-12 individual plants regenerated from independent hygromycin resistant calli, with several carrying simple T-DNA insertions. In lane WT, DNA from wild-type untransformed O. sativa cv Nipponbare as a negative control shows no hybridization.

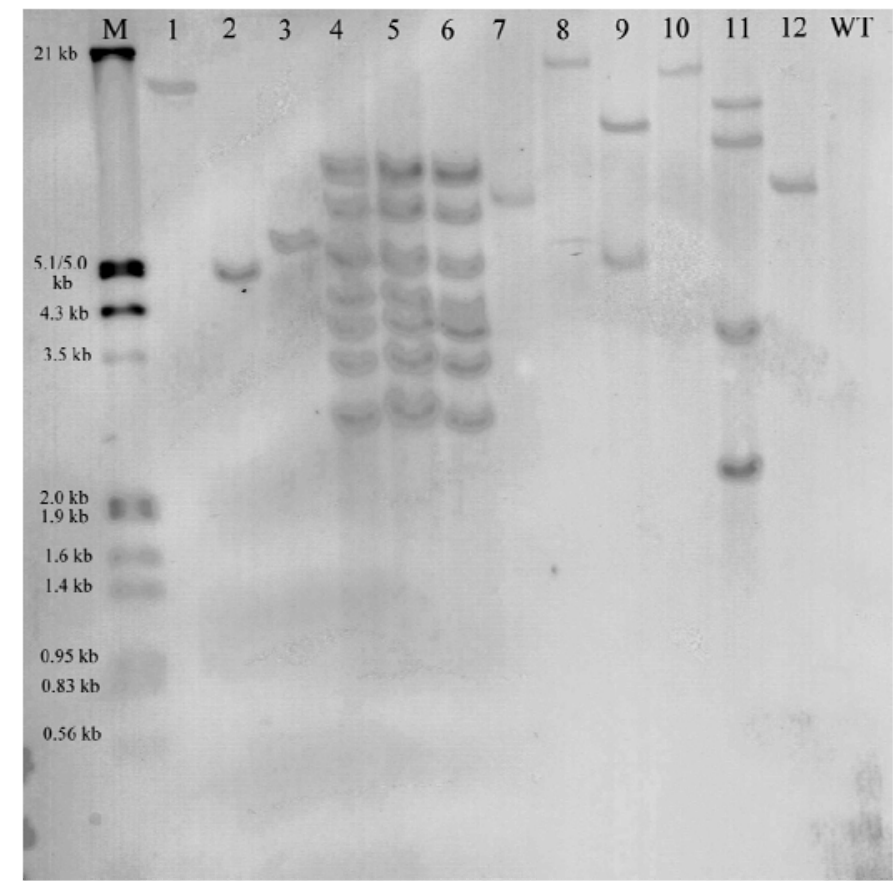

\subsection{Histochemical Analysis of gusA Reporter Transgenic Plants}

Histochemical analysis of Zm13Pro::GUS and OsUbiPro::GUS expression was performed in whole plants throughout their development to determine whether Zm13Pro::barnase expression might adversely affect plant health or morphology of transgenic events. Histochemical analyses for GUS was conducted on a spectrum of tissues and organs for all pZm13Pro::GUS $\mathrm{T}_{0}$ and $\mathrm{T}_{1}$ plants throughout their development, and comparable samples from pOsUbiPro::GUS and negative nontransformed controls were subjected to identical analyses. Vegetative organs including young, maturing and adult leaf, intercalated leaf meristematic regions, stem segments, root apices and mature root segments were stained for GUS according to standard procedures and visualized using dissecting light microscopy. Inflorescence and floral tissues, including spikelets, isolated anthers and pollen of $T_{0}$ and $T_{1}$ plants were also assayed using standard histochemical GUS staining. All tissues and organs of the pOsUbiPro::GUS $\mathrm{T}_{0}$ events stained positive for GUS activity (Figure 7A top); portions of tissues and 
organs from each of the $\mathrm{T}_{1}$ offspring pOsUbiPro::GUS events were analyzed by histochemical GUS staining, and gusA PCR-positive $\mathrm{T}_{1}$ offspring were shown to express gus $A$ in a fashion identical to that of the $\mathrm{T}_{0}$ plants. Taken together, these results provided a clear demonstration of constitutive gusA expression (see Figure 7A bottom) in pOsUbiPro::GUS events. The non-transformed controls did not show any spurious or background GUS stain in any tissues or organs.

Figure 7. GUS activity in transgenic events. Adult leaves are shown in the top panel, mature flowers shown in the bottom panel. (A) GUS positive pOsUbiPro::GUS control shows strong activity in all observed tissues and organs; (B) pZm13Pro::GUS T event 30 showing ectopic expression in mature vascular tissue in leaves and floral structures; (C) pZm13Pro::GUS $\mathrm{T}_{0}$ event 8 showing no GUS activity in leaves or the vasculature in the mature flowers. Pollen from gusA hpt PCR-positive $\mathrm{T}_{1}$ plants of this event stains positive for GUS activity (see Figure 6 ). Scale bar $=0.6 \mathrm{~cm}$.

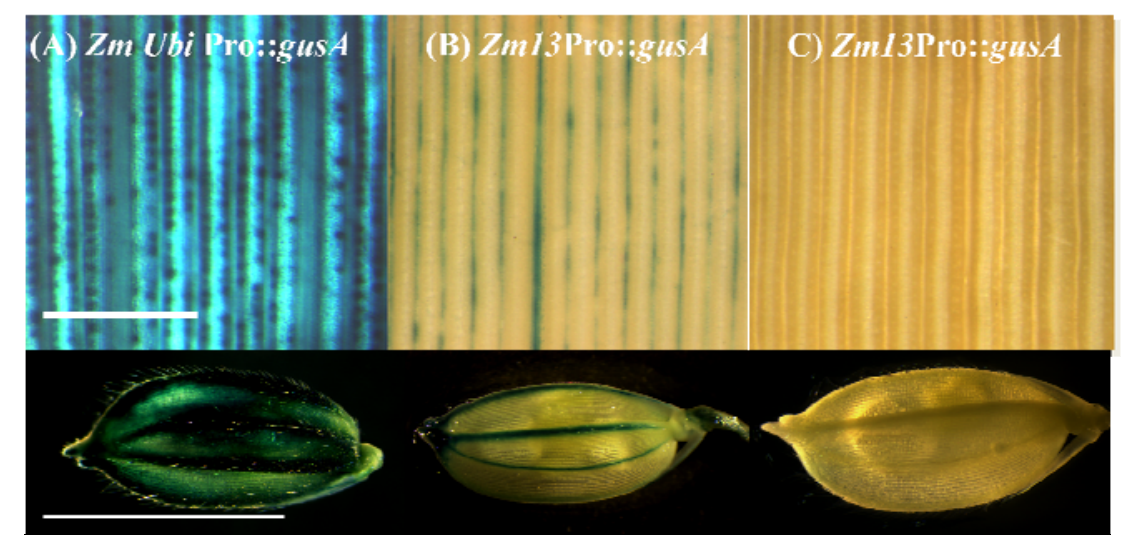

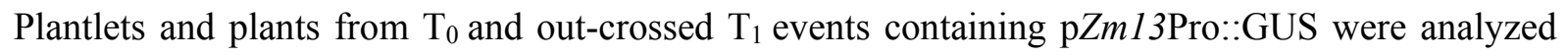
using the same procedures as for pOsUbiPro::GUS events. Plantlets and plants derived from all 13 pZm13Pro::GUS events that had stained positive (but variable or mottled) for GUS activity in their embryogenic calli also showed ectopic GUS activity which was localized exclusively to vascular tissue in regenerated $\mathrm{T}_{0}$ plantlets and plants throughout their vegetative tissues and organs (Figure 7B top) and in vascular tissues of floral structures (Figure 7B bottom). Of the $44 \mathrm{~T}_{0}$ events, 24 exhibited no GUS activity in stems, roots, leaves, or glumes whereas $20 \mathrm{~T}_{0}$ events exhibited GUS activity in the vascular tissue of adult leaves and floral structures.

As indicated concerning ectopic expression in embryogenic callus, if Zm13Pro::barnase expression was also ectopically expressed in a similar manner, it is likely that these events would not be recovered as whole plants or would at least be phenotypically abnormal. However, significant numbers of independent transgenic events were recovered with pZm13Pro::GUS, and these events did not show GUS activity in either vegetative (Figure 7C top) or floral structures (Figure 7C bottom). This indicated that Zm13Pro::barnase events could be also recovered and expected to be phenotypically normal. In previous studies using the double enhancer CaMV35S promoter driving a selectable marker gene, unexpected and spurious transgene expression characteristics were observed to result from interactions between the enhancer elements present in this promoter and neighboring transgenes, with the $35 \mathrm{~S}$ enhancer elements effectively overriding the control elements directly linked to the transgenes 
of interest [33,54-56]. Replacement of the double enhancer 35S promoter by alternative control elements corrected for these anomalies $[55,56]$, and this may also apply here.

Pollen specificity for Zm13Pro::GUS expression was evaluated in mature flowering $\mathrm{T}_{0}$ and $\mathrm{T}_{1}$ plants and compared with controls. Just prior to anthesis, mature anthers were isolated and collected from wild type controls, pOsUbiPro::GUS transgenics, and all $\mathrm{T}_{0}$ events and selected $\mathrm{T}_{1}$ lines of pZm13Pro::GUS transgenics and subjected to histochemical GUS staining. The wild type controls did not show any artifactual or background GUS staining in any anther tissues or pollen (Figure 8A). Anthers collected from $\mathrm{T}_{1}$ pOsUbiPro::GUS offspring plants carrying the transgenes showed expression throughout all anther tissues and pollen (Figure 8B). GUS activity in mature anthers from $\mathrm{T}_{1} \mathrm{pZm}$ 13Pro::GUS offspring plants, testing PCR positive for both the hpt and gusA transgenes, shows segregating and Zm13-driven pollen-specific GUS activity. This demonstrates that linked transgenes are co-integrated and expressed with pollen specific Zm13Pro::GUS expression. These results further indicate that Zm13Pro:barnase should behave similarly to drive pollen specific barnase expression and be co-integrated with a linked trait, such as the herbicide tolerance marker bar.

Figure 8. GUS activity in mature anthers from $T_{1}$ transgenic events. (A) Wild-type non-transgenic negative control; (B) pOsUbiPro::GUS $\mathrm{T}_{1}$ anther showing GUS activity throughout all anther tissues and pollen; (C) pZm13Pro::GUS $T_{1}$ event segregating $\sim 1: 1$ for GUS activity. Scale bars $=0.3 \mathrm{~cm}$.

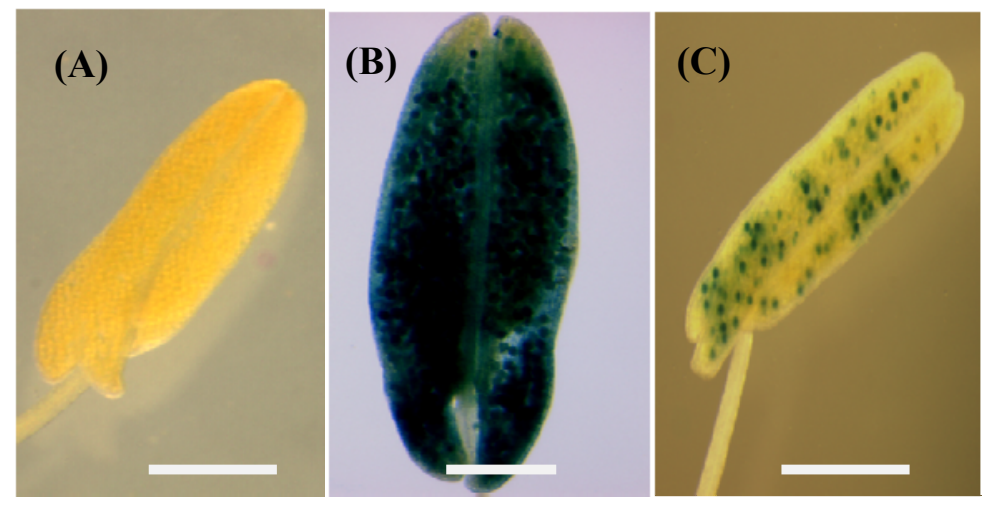

\subsection{Expression Analysis of pZm13Pro::barnase Transgenic Plants}

The ability for $Z m 13$ to function and confer tissue specific expression resulting in plants with pollen sterility was tested in $T_{1}$ transgenic plants using this promoter to drive the expression of the cytotoxic gene barnase. Results from the tissue and developmental analysis of pZm13Pro::GUS transgenics indicate that, in the majority of transformants, Zm13Pro::GUS is pollen specific and inherited as a single Mendelian trait which co-integrated with its selectable marker gene. To test the ability of this promoter to drive pollen specific cytotoxicity by barnase, gusA was replaced by the ribonuclease barnase; also, the plant selectable marker was changed to include an herbicide-tolerance trait gene, bar [57], resulting in $\mathrm{pZm13Pro::barnase} \mathrm{(see} \mathrm{Figure} \mathrm{1C).} \mathrm{This} \mathrm{allows} \mathrm{for} \mathrm{ease} \mathrm{of} \mathrm{phenotypic} \mathrm{analysis}$ as the herbicide Finale ${ }^{\circledR}(3 \% \mathrm{v} / \mathrm{v})$ can be applied to individual leaves as a nondestructive assay for the presence and expression of the bar marker gene. This assay was used to follow the segregation of the

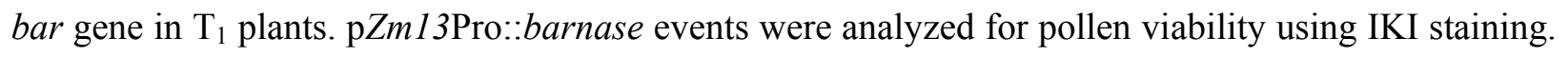


Mature anthers were collected from $T_{0}$ plants and from $T_{1}$ plants that tested positive for herbicide tolerance using the paint assay. Pollen was stained just prior to and during anthesis and analyzed for pollen viability (Figure 9). Pollen viability data was collected immediately after samples were stained in 5\% IKI solution and analyzed using brightfield and/or nomarski light microscopy. Pollen from $\mathrm{T}_{1}$ progeny which tested herbicide resistant and PCR positive for both bar and barnase transgenes showed approximately 1:1 segregation for pollen viability (Figure 9). This result clearly demonstrates that the $\mathrm{Zm} 13$ promoter is capable of directing pollen specific gene expression and conferring stable pollen sterility when linked to a selectable marker as a gene of interest. Subsequently, progeny of the $\mathrm{T}_{1}$ out-crossed $\mathrm{pZm13Pro::barnase}$ plants have been selfed through three generations.

Figure 9. Segregation ( 1:1) of viable and non-viable pollen (dark and light) in $\mathrm{T}_{1}$ progeny of a $\mathrm{pZm13Pro::barnase}$ event is shown via IKI staining. Pollen was collected from just prior to anthesis and stained in 5\% IKI solution. Scale bar $=0.5 \mu \mathrm{m}$.

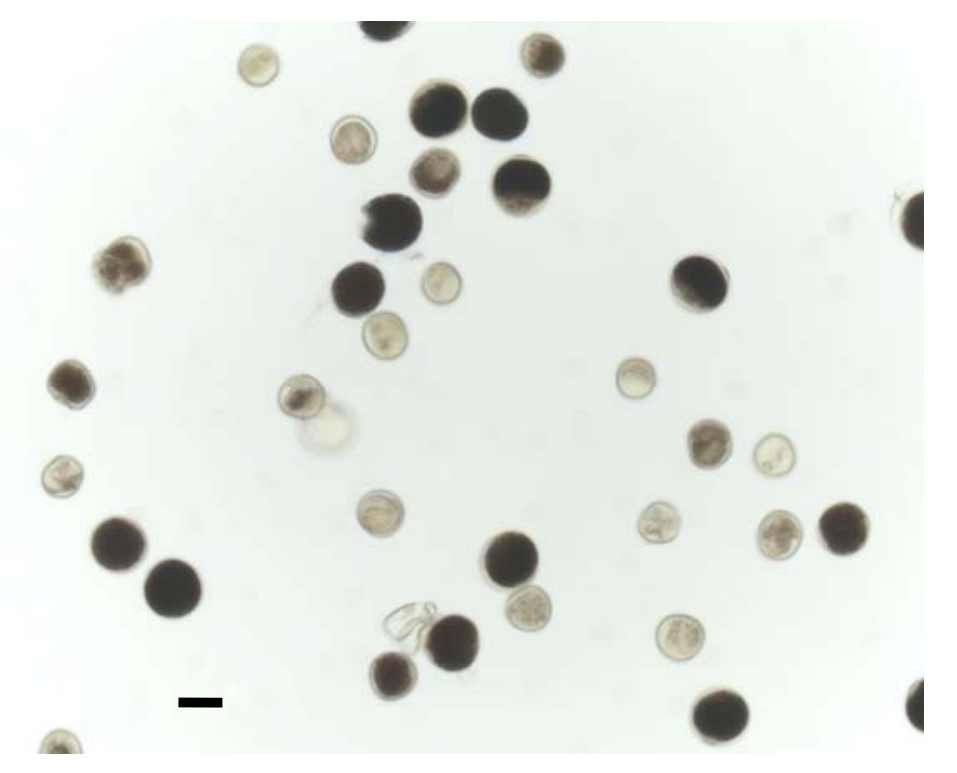

It is possible that low levels of expression from this promoter, which may be below detectable levels using histochemical GUS analysis, could cause deleterious effects on plant growth when driving barnase expression. Previous studies using tapetum specific promoters to drive barnase expression successfully show anther ablation resulting in male sterility [34], however, this system suffered from side effects caused by non-specific promoter driven expression in other tissues resulting in observable negative effects on normal plant growth and development. Our $\mathrm{T}_{0}$ plants appeared normal with respect to their non-transgenic controls in all respects of plant growth. In addition, the plants were hand pollinated by the breeders at the International Center for Tropical Agriculture (personal communication), who have extensive experience with hand pollinations in rice. Based on their experience, the seed set recovery was the same as that observed in hand emasculated crosses. Therefore, other than pollen fertility, the floral and reproductive structures appeared to be normal in these plants. However, it is possible that there was low-level expression in other tissues, but if such expression occurred, it appears to not have negatively impacted the plants. 


\section{Experimental Section}

\subsection{Plant Material}

The induction of embryogenic callus and genetic transformation was carried out using wild-type Oryza sativa ssp. Japonica cv. Nipponbare in all experiments. Seed was stored at $4{ }^{\circ} \mathrm{C}$ until dehusked, sterilized, and plated on callus-induction medium.

\subsection{Induction of Embryogenic Callus}

Mature seeds were de-husked with sand paper and gently shaken in $70 \%$ ethanol for two min, rinsed 5 times in sterile distilled water, and then surface-sterilized by two 30 min cycles of rapid shaking in $50 \%$ (v/v) Clorox bleach (5.25\% sodium hypochlorite) plus 0.2\% (v/v) Tween 20 (Polysorbate 20). Surface sterilized seed was rinsed three times in sterile distilled water and then placed onto callus-induction medium containing $\mathrm{N}_{6}$ basal salts and vitamins [58], $30 \mathrm{~g} \cdot \mathrm{L}^{-1}$ sucrose, $1 \mathrm{~g} \cdot \mathrm{L}^{-1}$ casein

hydrolysate, $2 \mathrm{mg} \cdot \mathrm{L}^{-1}$ 2,4-dichlorophenoxyacetic acid (2,4-D), $1 \mathrm{mg} \cdot \mathrm{L}^{-1} \quad$ 6-furfurylaminopurine (kinetin) and $3 \mathrm{~g} \cdot \mathrm{L}^{-1}$ Gelrite. The final $\mathrm{pH}$ of the medium was 5.8. Culture plates containing sterilized seed were stored at $25{ }^{\circ} \mathrm{C}$ in darkness for 3 to 6 weeks. During this time, embryogenic calli were visually selected and sub-cultured every 14 days on callus-induction medium.

\subsection{Agrobacterium Strains and Plasmids}

A cassette containing a translational fusion of a maize pollen specific promoter $Z m 13$ [48] and the E. coli $\beta$-glucuronidase gene (uidA or gusA) [59] was inserted into the binary vector pCAMBIA 1200 (GenBank Accession Number AF234292). Briefly, the Zm13 promoter was amplified from inbred line W22 maize genomic DNA via PCR using the forward primer (5'-GAATTCGCTTTTTGCG TCACGCTTGTA-3') and reverse primer (5'-CCATGGGTGGATGTCGGAGGAAAAGGGC-3'); the restriction sites, EcoRI and $N c o$ I respectively, were introduced at the 5' and $3^{\prime}$ end of the promoter for cloning purposes and are shown here underlined. The amplification reaction was performed using the Expand High Fidelity PCR System (Roche USA) according to the manufacturer's recommendations. The resulting PCR product was digested with the restriction enzymes EcoRI and NcoI (New England Biolabs, Ipswich, MA, USA), and ligated into the predigested plasmid pRTL2-GUS [59]. The resulting plasmid was further digested with EcoRI and Pst I and treated with T4 DNA polymerase (New England Biolabs) to generate a blunt ended fragment of $\sim 3.5 \mathrm{~kb}$ in size containing a translational fusion between the $Z m 13$ promoter and the gusA gene. This fragment was then subcloned into pCAMBIA 1200 digested previously with EcoRI and treated with Klenow enzyme (New England Biolabs). The resulting pCAMBIA1200::Zm13-GUS plasmid was fully sequenced (W. Keck-Sequencing Facility, Yale University) and is referred to herein as pZm13Pro::GUS. The pZm13Pro::barnase construct was derived from pZm13Pro::GUS via replacement of hpt with bar as the selectable marker and replacement of gusA with the barnase sequence. Agrobacterium strain LBA4404 (Invitrogen USA) was transformed with the final constructs via electroporation. The pOsUbiPro::GUS construct for this study was the kind gift of Dr. Hong Luo, Clemson University South Carolina, USA. 


\subsubsection{Agrobacterium-Mediated Transformation and Co-cultivation}

A. tumefaciens cultures derived from single colonies were grown in $2 \mathrm{~mL}$ YEP medium at $28{ }^{\circ} \mathrm{C}$ with shaking $(200 \mathrm{rpm})$ until $\mathrm{OD}_{600}$ equaled $1.0-1.4$. Cells were then pelleted by centrifugation at $3220 \times \mathrm{g}$ for $10 \mathrm{~min}$ and resuspended in liquid callus-induction medium supplemented with $100 \mu \mathrm{M}$ acetosyringone. The final density $\left(\mathrm{OD}_{600}\right)$ of the resuspended Agrobacterium was adjusted to 1.0. One to two weeks prior to co-cultivation, embryogenic calli were divided into approximately 1- to 2-mm pieces and placed on callus-induction medium (approximately 50 calli per plate) containing $100 \mu \mathrm{M}$ acetosyringone. To initiate infection, $10 \mu \mathrm{L}$ aliquots of Agrobacterium suspension $\left(\mathrm{OD}_{600}=1.0\right)$ supplemented with $100 \mu \mathrm{M}$ acetosyringone were applied to each callus, followed by 3 days of co-cultivation in darkness at $28^{\circ} \mathrm{C}$.

\subsection{Selection of Transformed Colonies and Regeneration of Transgenic Plants}

Following co-cultivation, embryogenic calli were transferred to callus induction medium

supplemented with $50 \mathrm{mg} \cdot \mathrm{L}^{-1}$ hygromycin $\mathrm{B}$ and $125 \mathrm{mg} \cdot \mathrm{L}^{-1}$ carbenicillin and sub-cultured every 14 days on this medium for a period of 8 to 10 weeks at $25{ }^{\circ} \mathrm{C}$ in darkness. Callus colonies surviving this period of selection were used for callus proliferation and plant regeneration. Proliferation media contained $\mathrm{N}_{6}$ salts and vitamins [58] with $20 \mathrm{~g} \cdot \mathrm{L}^{-1}$ sucrose, $30 \mathrm{~g} \cdot \mathrm{L}^{-1}$ sorbitol, $2 \mathrm{mg} \cdot \mathrm{L}^{-1}$ 2,4-dichlorophenoxyacetic acid (2,4-D), $0.5 \mathrm{mg} \cdot \mathrm{L}^{-1}$ benzyladenine (BA), and $3.0 \mathrm{~g} \cdot \mathrm{L}^{-1}$ Gelrite supplemented with hygromycin and carbenicillin as above. Plant regeneration medium $\left(\mathrm{R}_{1}\right)$ contained MS salts and vitamins [60] with $30 \mathrm{~g} \cdot \mathrm{L}^{-1}$ sucrose, $50 \mathrm{mg} \cdot \mathrm{L}^{-1}$ tryptophan, $2.5 \mathrm{mg} \cdot \mathrm{L}^{-1}$ 6-furfurylaminopurine (kinetin), $\quad 0.1 \mathrm{mg} \cdot \mathrm{L}^{-1}$ 1-naphtylacetic acid (NAA) and $3 \mathrm{~g} \cdot \mathrm{L}^{-1}$ Gelrite supplemented with hygromycin and carbenicillin. Calli selected for regeneration were maintained on $\mathrm{R}_{1}$ medium at $25^{\circ} \mathrm{C}$ in darkness for approximately 7 days and subsequently moved into a lighted growth chamber (40w fluorescent lighting, $29^{\circ} \mathrm{C}$ ). Regenerated plants were transferred to a second regeneration medium $\left(R_{I I}\right)$ until roots were well developed. $R_{I I}$ medium was $R_{I}$ medium with kinetin and NAA removed. Plants with well-developed roots (3-5 weeks) were then transferred to soil and grown under greenhouse conditions until flowering and maturity.

\subsection{Molecular Characterization of Transgenic Plants}

Total genomic DNA was isolated as described by Chen and Dellaporta [53] with only minor modifications. PCR was performed on the initial transformant population $\left(\mathrm{T}_{0}\right)$ and $\mathrm{T}_{1}\left(\mathrm{~T}_{0} \mathrm{x}\right.$ wildtype cv. Nipponbare or $\mathrm{T}_{0}$ selfed) progeny using gusA and hpt (hygromycin phosphotransferase) specific primers. For amplification and detection of the gusA transgene, primers 5'-AAAGTGTACGTA TCACCGTTTGTGT-3' (forward) and 5'-CAGTAAAGTAGAACGGTTTGTGGTT-3' (reverse) were used with an expected internal amplification product of $494 \mathrm{bp}$ and for hpt the primers were 5'-ACATTGTTGGAGCCGAAATC-3' (forward) and 5'-AGCGAGAGCCTGACCTAT-3' (reverse), resulting in amplification of a $362 \mathrm{bp}$ internal fragment. The amplification reactions were carrying out using Taq DNA polymerase with Standard Taq Buffer according to the manufacturer's specifications (New Englnad Biolabs). Amplification parameters were 1 cycle of $4 \mathrm{~min}$ at $94{ }^{\circ} \mathrm{C}$ (denaturation), then $1 \mathrm{~min}$ at $58{ }^{\circ} \mathrm{C}$ (annealing), and $2 \mathrm{~min}$ at $72{ }^{\circ} \mathrm{C}$ (elongation), followed by 35 cycles of $30 \mathrm{~s}$ at 
$94{ }^{\circ} \mathrm{C} / 30$ s at $58{ }^{\circ} \mathrm{C} / 2 \mathrm{~min}$ at $72{ }^{\circ} \mathrm{C}$ (elongation), and a final cycle of 7 min at $72{ }^{\circ} \mathrm{C}$. PCR products were visualized on a $1.2 \%(\mathrm{w} / \mathrm{v})$ agarose gel containing ethidium bromide.

Southern blot analyses were performed on plants carrying T-DNA insertions from pZm13Pro::GUS using $10 \mu \mathrm{g}$ of genomic DNA digested with the restriction endonuclease $E c o R \mathrm{~V}$, which cuts once within the hpt plant selectable marker cassette approximately $2.1 \mathrm{~kb}$ away from the T-DNA left border sequence. Twenty $\mu \mathrm{g}$ of NcoI-digested wild-type genomic DNA was included as a negative hybridization control. The digested DNA was size-fractionated by agarose gel electrophoresis in a $0.8 \%(\mathrm{w} / \mathrm{v})$ agarose gel and transferred to either a Hybond ${ }^{\mathbf{T M}} \mathrm{N}^{+}$positively charged nylon membrane (GE Healthcare, Piscataway, NJ, USA) or Roche Nylon Membranes ${ }^{\text {TM }}$, positively charged (Roche Applied Science, IN, USA), by high-salt capillary transfer [61]. The resulting membranes were hybridized to a 364 bp hpt probe generated by PCR and gel purified according to the manufacturer's instructions (Qiagen Gel Extraction Kit, Qiagen). The hpt probe was digoxigenin (DIG)-labeled according to the manufacturer's protocol (DIG High Prime DNA labeling and detection starter kit $\mathrm{I}^{\mathrm{TM}}$ ) and pre-hybridization, hybridization, and post-hybridization washes were done according to the standard protocol. The digoxigenin-hybridized fragments were detected by enzyme immunoassay and visualized using colorimetric substrates according to the manufacturer's instructions. Digital images of the membranes were captured using a Kodak Image Station 4000MM and viewed with molecular imaging software (Carestream Health, Inc.).

\subsection{Staining for GUS Activity}

$\beta$-glucuronidase, encoded by the E. coli gene uidA (aka gusA), catalyzes the cleavage of a number of commercially obtainable $\beta$-glucuronides. GUS activity in hygromycin-resistant calli, adult leaves, stems, roots, and mature pollen ( 6 complete flowers per inflorescence per plantlet) of $\mathrm{T}_{0}$ and $\mathrm{T}_{1}$ plants was assayed by histochemical staining with $1 \mathrm{mM}$ 5-bromo-4-chloro-3-indolyl-b- $d$-glucuronic acid (X-Gluc, Gold Biotechnology, St. Louis, Missouri, USA) as described in Jefferson [59]. Hygromycin B-resistant calli surviving selection was gently macerated, placed under vacuum infiltration for 15 min, and incubated at $37^{\circ} \mathrm{C}$ overnight in $300-500 \mu \mathrm{L}$ of reaction buffer containing X-Gluc. Whole flowers, approximately $2 \mathrm{~mm}$-thick stem and root cross-sections, and roughly $1 \mathrm{~cm}^{2}$ pieces of adult leaf tissue were submerged in 300-500 $\mu \mathrm{L}$ of reaction buffer, vacuum infiltrated for $15 \mathrm{~min}$, and incubated at $37{ }^{\circ} \mathrm{C}$ overnight. Wild-type tissues were included in all assays as negative controls. GUS activity in assayed tissues was then examined microscopically and documented via photomicroscopy.

\section{Conclusions}

As a single Mendelian trait, pollen sterility presents a promising approach to both gene confinement and breeding for genetically modified crops. Analysis of expression characteristics of a maize pollen specific promoter (Zm13Pro) shows that when linked to a reporter gene, such as gusA, a subset of transgenics is pollen specific and when linked to a cytotoxic gene (i.e., Zm13Pro::barnase) Zm13Pro can confer pollen sterility. Perhaps stable knockouts could be created against orthologous targets using Zinc Finger Nuclease (ZFN) or Transcription Activator-Like Effector Nuclease (TALEN) modifications to direct sterility functions [62-69] avoiding any potential side effects of low levels of cytotoxin gene expression in non-target tissues. This study also shows that pollen specific expression 
is co-integrated and capable of co-expression when linked to a trait gene of interest. We show that Zm13 transgene cassettes were stably inherited together with linked resistance markers, as exemplified in this study by either D35SPro::hpt or D35SPro::bar.

Stable nuclear pollen sterility may function as an important breeding tool in some crop species. Plant breeders and seed producers have exploited a number of inherent genetic systems, including cytoplasmic male sterility (CMS), to produce male-sterile plants and thereby control pollination in breeding lines in many species [70]. CMS has been observed in over 150 plant species including maize, rice, and wheat [70,71]. Detasseling (for maize) or emasculation procedures and/or CMS systems are lacking or deficient in many important crops still grown as inbred or partially domesticated varieties [36,72,73]. Given the accumulated knowledge of CMS systems and the desirability of developing male sterility systems lacking the shortcomings of most CMS systems, a number of strategies for engineering male sterility have been developed to generate male-sterile plants as breeding materials and for gene confinement strategies [2,73,74]. The use of hemizygous plants with the pollen sterility cassette linked to a trait gene of interest would be advantageous for breeding of certain species which may require the additional wild-type pollen. These plants contain pollen which is nonviable only when it carries a transgene linked to the sterility trait; this could provide a sufficient non-GM pollen cloud to ensure fertility and seed set.

The development of strategies for the prevention of gene flow in genetically modified plants is currently a topic of wide concern. A major component of gene flow in flowering plants is pollen-mediated transfer [2,9,11,37]. Several field studies and risk assessments have been performed on both annual and/or self-pollinating transgenic crops [25,26,75-78] and transgenic herbicide-resistant perennial grasses [12-15,26,79]. These studies have confirmed pollen-mediated gene flow from transgenic crop plants to non-transgenic plants and in some cases, sexually compatible wild relatives; thus, disruption of pollen development, function, or movement is seen as a possible strategy to mitigate the risk of pollen-mediated transgene escape. Prior research has demonstrated that the $Z m 13$ promoter can direct pollen-specific expression in stably-transformed transgenic dicot plants $[46,47]$. We show here that $Z m 13$ is capable of directing pollen specific gene expression and conferring stable pollen sterility in a transgenic monocot (rice). Therefore, this strategy may prove useful for breeding purposes for both food and bioenergy crops.

However, several questions arise when considering current research on gene confinement and the degree of stringency required for release of a GM perennial plant into the environment for commercial applications, such as is anticipated for the production of switchgrass and other perennials as biofuels feedstocks. Will the control of pollen flow alone be adequate, or will a control for seed scatter, or vegetative tillering also be required? Can a system be developed that will be flexible enough to allow additional gene stacking without the cost and time involved with the production of new transgenic lines? GM technologies with significant potential for bioenergy crop improvement may be difficult or impossible to commercialize without an adequate gene confinement strategy that will allow them to progress through the deregulation process. Perhaps stacked sterility and gene confinement strategies will need to be in place as "fail safe" mechanisms to allow deregulation, and pollen sterility may function as one component. 
We have evaluated the feasibility of using a promoter ( $\mathrm{m}$ 13Pro) to generate pollen sterility lines for gene confinement and breeding purposes in transgenic rice (Oryza sativa ssp. Japonica cv. Nipponbare) as a monocot proxy for bioenergy grasses. In this study, we have described expression of a gusA reporter gene driven by $\sim 1 \mathrm{~kb}$ of a maize promoter element from the pollen-specific gene, Zm13 [40]. These results clearly demonstrate expression of the Zm13Pro::gusA transgene in all transformants. This evaluation showed: (1) co-transformation and expression of a selectable marker gene cassette (D35S::hpt::35SA) with Zm13Pro driving expression of a reporter gene (gusA) and a cytotoxin gene (barnase) in transgenic rice plants; (2) Zm13Pro::gusA was expressed exclusively in the pollen in a subset of the total pZm13Pro::gusA events recovered, whereas another subset exhibited unexpected GUS activity localizing to vascular tissues in some transgenic plants in addition to the pollen; (3) the ability of Zm13Pro to confer pollen sterility via barnase expression was stably inherited with linked trait genes of interest, in this case tolerance to glufosinate ammonium herbicides. We are currently investigating the utility of the constructs presented in this study for breeding and gene confinement in transgenic switchgrass.

\section{Acknowledgments}

The final pOsUbiPro::GUS construct used for this study was the kind gift of Hong Luo, Clemson University, South Carolina, USA. We also thank Edgar Torres and Cezar Martinez at CIAT, Cali, Colombia, for conducting the out-crossing experiments to produce the $\mathrm{T}_{1}$ pZm13Pro::gusA and pZm13Pro::barnase lines used in these experiments. This research was supported by DOE Award Number: DE-FG-36-08GO88070 Genetic Improvement of Switchgrass, and NSF/BREAD/IOS 0965420 BREAD: Hybrid technologies for heterosis in rice and related cereals.

\section{References}

1. Brutnell, T.; Frommer, W. Food for thought: Plant research remains grossly underfunded, despite the demand for increased crop production to support a growing population. The Scientist, June 2012, pp. 23-24.

2. Kausch, A.P.; Hague, J.; Oliver, M.; Li, Y.; Daniell, H.; Mascia, P.; Stewart, C.N. Genetic modification in dedicated bioenergy crops and strategies for gene confinement. In Plant Biotechnology for Sustainable Production of Energy and Co-products; Mascia, P.N., Scheffran, Jr., Widholm, J.M., Eds.; Springer Berlin Heidelberg: Berlin, Germany, 2010; Volume 66, pp. 299-315.

3. Gressel, J. Transgenics are imperative for biofuel crops. Plant Sci. 2008, 174, 246-263.

4. Gruskin, D. Agbiotech 2.0. Nat. Biotechnol. 2012, 30, 211-214.

5. Lusser, M.; Parisi, C.; Plan, D.; Rodriguez-Cerezo, E. Deployment of new biotechnologies in plant breeding. Nat. Biotechnol. 2012, 30, 231-239.

6. Stewart, C.N.J. Genetically Modified Planet: Environmental Impacts of Genetically Engineered Plants; Oxford University Press: New York, NY, USA, 2004; p. 240.

7. Agnostic about agriculture. Nat. Biotechnol. 2012, 30, 197-197.

8. Wolfenbarger, L.L.; Phifer, P.R. The ecological risks and benefits of genetically engineered plants. Science 2000, 290, 2088-2093. 
9. Kausch, A.P.; Hague, J.; Oliver, M.; Watrud, L.S.; Mallory-Smith, C.; Meier, V.; Stewart, C.N. Gene flow in genetically engineered perennial grasses: Lessons for modification of dedicated bioenergy crops. In Plant Biotechnology for Sustainable Production of Energy and Co-products; Mascia, P.N., Scheffran, Jr., Widholm, J.M., Eds.; Springer Berlin Heidelberg: Berlin, Germany, 2010; Volume 66, pp. 285-297.

10. Moon, H.S.; Abercrombie, J.M.; Kausch, A.P.; Stewart, C.N. Sustainable use of biotechnology for bioenergy feedstocks. Environ. Manag. 2010, 46, 531-538.

11. Kausch, A.P.; Hague, J.; Oliver, M.; Li, Y.; Daniell, H.; Mascia, P.; Watrud, L.S.; Stewart, C.N. Transgenic perennial biofuel feedstocks and strategies for bioconfinement. Biofuels 2010, 1, 163-176.

12. Reichman, J.R.; Watrud, L.S.; Lee, E.H.; Burdick, C.A.; Bollman, M.A.; Storm, M.J.; King, G.A.; Mallory-Smith, C. Establishment of transgenic herbicide-resistant creeping bentgrass (Agrostis stolonifera L.) in nonagronomic habitats. Mol. Ecol. 2006, 15, 4243-4255.

13. Watrud, L.S.; Lee, E.H.; Fairbrother, A.; Burdick, C.; Reichman, J.R.; Bollman, M.; Storm, M.; King, G.; van de Water, P.K. Evidence for landscape-level, pollen-mediated gene flow from genetically modified creeping bentgrass with CP4 EPSPS as a marker. Proc. Nat. Acad. Sci. USA 2004, 101, 14533-14538.

14. Wipff, J.K.; Fricker, C. Gene flow from transgenic creeping bentgrass (Agrostis stolonifera L.) in the Willamette valley, Oregon. Int. Turfgrass Soc. Res. J. 2001, 9, 224-242.

15. Zapiola, M.L.; Campbell, C.K.; Butler, M.D.; Mallory-Smith, C.A. Escape and establishment of transgenic glyphosate-resistant creeping bentgrass agrostis stolonifera in oregon, USA: A 4-year study. J. Appl. Ecol. 2008, 45, 486-494.

16. Zapiola, M.L.; Mallory-Smith, C.A.; Thompson, J.H.; Rue, L.J.; Campbell, C.K.; Butler, M.D. Gene escape from glyphosate-resistent creeping bentgrass fields: Past, present, and future. In Proceedings of the Western Society of Weed Science, Portland, OR, USA, 13-15 March 2007; Western Society of Weed Science: Las Cruces, NM, USA; Volume 60, p. 18.

17. Luo, K.; Duan, H.; Zhao, D.; Zheng, X.; Deng, W.; Chen, Y.; Stewart, C.N., Jr.; McAvoy, R.; Jiang, X.; Wu, Y.; He, A.; Pei, Y.; Li, Y. "GM-gene-deletor": Fused loxP-FRT recognition sequences dramatically improve the efficiency of FLP or CRE recombinase on transgene excision from pollen and seed of tobacco plants. Plant Biotechnol. J. 2007, 5, 263-274.

18. Oliver, M.J.; Quisenberry, J.E.; Trolinder, N.L.G.; Keim, D.L. Control of Plant Gene Expression. U.S. Patent 5925808, 20 July 1999.

19. Oliver, M.J.; Quiseberry, J.E.; Trolinder, N.L.G.; Keim, D.L. Control of Plant Gene Expression. U.S. Patent 5723765, 3 March 1998.

20. Oliver, M.J.; Quiseberry, J.E.; Trolinder, N.L.G.; Keim, D.L. Control of Plant Gene Expression. U.S. Patent 5977441, 2 November 1999.

21. Djukanovic, V.; Lenderts, B.; Bidney, D.; Lyznik, L.A. A cre::FLP fusion protein recombines FRT or loxP sites in transgenic maize plants. Plant Biotechnol. J. 2008, 6, 770-781.

22. Ow, D.W. Gm maize from site-specific recombination technology, what next? Curr. Opin. Biotechnol. 2007, 18, 115-120.

23. Srivastava, V.; Ow, D.W. Rare instances of Cre-mediated deletion product maintained in transgenic wheat. Plant Mol. Biol. 2003, 52, 661-668. 
24. Mallory-Smith, C.; Zapiola, M. Gene flow from glyphosate-resistant crops. Pest Manag. Sci. 2008, 64, 428-440.

25. Ellstrand, N.C.; Hoffman, C.A. Hybridization as an avenue of escape for engineered genesStrategies for risk reduction. BioScience 1990, 40, 438-442.

26. Belanger, F.C.; Meagher, T.R.; Day, P.R.; Plumley, K.; Meyer, W.A. Interspecific hybridization between Agrostis stolonifera and related Agrostis species under field conditions. Crop Sci. 2003, 43, 240-246.

27. Christoffer, P.M. Transgenic glyphosate resistant creeping bentgrass: Studies in pollen-mediated transgene flow. Master's Thesis, Washington State University, 2003.

28. Pineyro-Nelson, A.; Van Heerwaarden, J.; Perales, H.R.; Serratos-Hernandez, J.A.; Rangel, A.; Hufford, M.B.; Gepts, P.; Garay-Arroyo, A.; Rivera-Bustamante, R.; Alvarez-Buylla, E.R. Transgenes in mexican maize: Molecular evidence and methodological considerations for GMO detection in landrace populations. Mol. Ecol. 2009, 18, 750-761.

29. Snow, A. Unwanted transgenes re-discovered in oaxacan maize. Mol. Ecol. 2009, 18, 569-571.

30. Snow, A.A. Transgenic crops - Why gene flow matters. Nat. Biotechnol. 2002, 20, 542-542.

31. Chandler, S.; Dunwell, J.M. Gene flow, risk assessment and the environmental release of transgenic plants. Crit. Rev. Plant Sci. 2008, 27, 25-49.

32. De Block, M.; Debrouwer, D.; and Moens, T. The development of nuclear male sterility system in wheat: Expression of the barnase gene under the control of tapetum specific promoters. Theor. Appl. Genet. 1997, 95, 125-131.

33. Jagannath, A.; Bandyopadhyay, P.; Arumugam, N.; Gupta, V.; Kumar, P.; Pental, D. The use of spacer DNA fragment insulates the tissue-specific expression of a cytotoxic gene (barnase) and allows high-frequency generation of transgenic male sterile lines in Brassica juncea L. Mol. Breed. 2001, 8, 11-23.

34. Mariani, C.; Beuckeleer, M.; Truettner, J.; Leemans, J.; Goldberg, R. Induction of male sterility in plants by a chimaeric ribonuclease gene. Nature 1990, 374, 737-738.

35. Mariani, C.; Gossele, V.; Beuckeleer, M.D.; Block, M.D.; Goldberg, R.B.; Greef, W.D.; Leemans, J. A chimaeric ribonuclease-inhibitor gene restores fertility to male sterile plants. Nature 1992, 357, 384-387.

36. Chase, C.D. Genetically engineered cytoplasmic male sterility. Trends Plant Sci 2006, 11, 7-9.

37. Kausch, A.P.; Hague, J.; Deresienski, A.; Tilelli, M.; Longo, C., Jr.; Nelson, K. Male sterility and hybrid plant systems for gene confinement. In Plant Gene Containment, 1st ed.; Oliver, M.J., Li, Y., Eds.; Wiley-Blackwell: Ames, IA, USA, 2012; pp. 83-98.

38. Tanaka, J. Transgenic male sterility permits efficient recurrent selection in autogamous crops. Crop Sci. 2010, 50, 1124-1127.

39. Khan, M.S. Plant biology: Engineered male sterility. Nature 2005, 436, 783-785.

40. Hamilton, D.A.; Bashe, D.M.; Stinson, J.R.; Mascarenhas, J.P. Characterization of a pollen-specific genomic clone in maize. Sex. Plant Reprod. 1989, 2, 208-212.

41. Hanson, D.D.; Hamilton, D.A.; Travis, J.L.; Bashe, D.M.; Mascarenhas, J.P. Characterization of a pollen-specific cdna clone from zea mays and its expression. Plant Cell 1989, 1, 173-179.

42. Twell, D.; Wing, R.; Yamaguchi, J.; McCormick, S. Isolation and expression of an anther-specific gene from tomato. Mol. Gen. Genet. 1989, 217, 240-245. 
43. Ursin, V.M.; Yamaguchi, J.; McCormick, S. Gametophytic and sporophytic expression of anther-specific genes in developing tomato anthers. Plant Cell 1989, 1, 727-736.

44. Bate, N.; Twell, D. Functional architecture of a late pollen promoter: Pollen-specific transcription is developmentally regulated by multiple stage-specific and co-dependent activator elements. Plant Mol. Biol. 1998, 37, 859-869.

45. Eyal, Y.; Curie, C.; McCormick, S. Pollen specificity elements reside in $30 \mathrm{bp}$ of the proximal promoters of two pollen-expressed genes. Plant Cell 1995, 7, 373-384.

46. Guerrero, F.D.; Crossland, L.; Smutzer, G.S.; Hamilton, D.A.; Mascarenhas, J.P. Promoter sequences from a maize pollen-specific gene direct tissue-specific transcription in tobacco. Mol. Gen. Genet. 1990, 224, 161-168.

47. Hamilton, D.A.; Schwarz, Y.H.; Rueda, J.; Mascarenhas, J.P. Comparison of transient and stable expression by a pollen-specific promoter: The transformation results do not always agree. Sex. Plant Reprod. 2000, 12, 292-295.

48. Hamilton, D.A.; Roy, M.; Rueda, J.; Sindhu, R.K.; Sanford, J.; Mascarenhas, J.P. Dissection of a pollen-specific promoter from maize by transient transformation assays. Plant Mol. Biol. 1992, 18, 211-218.

49. Hamilton, D.A.; Schwarz, Y.H.; Mascarenhas, J.P. A monocot pollen-specific promoter contains separable pollen-specific and quantitative elements. Plant Mol. Biol. 1998, 38, 663-669.

50. Twell, D.; Yamaguchi, J.; McCormick, S. Pollen-specific gene expression in transgenic plants: Coordinate regulation of two different tomato gene promoters during microsporogenesis. Development 1990, 109, 705-713.

51. Twell, D.; Yamaguchi, J.; Wing, R.A.; Ushiba, J.; Mccormick, S. Promoter analysis of genes that are coordinately expressed during pollen development reveals pollen-specific enhancer sequences and shared regulatory elements. Genes \& Dev. 1991, 5, 496-507.

52. Wang, J.; Jiang, J.; Oard, J.H. Structure, expression and promoter activity of two polyubiquitin genes from rice (Oryza sativa L.). Plant Sci. 2000, 156, 201-211.

53. Chen, J.; Dellaporta, S. Urea-based plant DNA miniprep. In The Maize Handbook; Freeling, M., Walbot, V., Eds.; Springer-Verlag: New York, NY, USA, 1994; pp. 526-528.

54. Weigel, D.; Ahn, J.H.; Blázquez, M.A.; Borevitz, J.O.; Christensen, S.K.; Fankhauser, C.; Ferrándiz, C.; Kardailsky, I.; Malancharuvil, E.J.; Neff, M.M.; et al. Activation tagging in arabidopsis. Plant Physiol. 2000, 122, 1003-1014.

55. Yoo, S.Y.; Bomblies, K.; Yoo, S.K.; Yang, J.W.; Choi, M.S.; Lee, J.S.; Weigel, D.; Ahn, J.H. The $35 \mathrm{~S}$ promoter used in a selectable marker gene of a plant transformation vector affects the expression of the transgene. Planta 2005, 221, 523-530.

56. Zheng, X.; Deng, W.; Luo, K.; Duan, H.; Chen, Y.; McAvoy, R.; Song, S.; Pei, Y.; Li, Y. The cauliflower mosaic virus (CaMV) 35S promoter sequence alters the level and patterns of activity of adjacent tissue- and organ-specific gene promoters. Plant Cell Rep. 2007, 26, 1195-1203.

57. De Block, M.D.; Botterman, J.; Vandewiele, M.; Dockx, J.; Thoen, C.; Gossele, V.; Movva, N.R.; Thompson, C.; Montagu, M.V.; Leemans, J. Engineering herbicide resistance in plants by expression of a detoxifying enzyme. EMBO J. 1987, 6, 2513-2518. 
58. Chu, C.C.; Want, C.C.; Sun, C.S.; Hsu, C.; Yin, K.C.; Chu, C.Y.; Bi, F.Y. Establishment of an efficient medium for anther culture of rice, through comparative experiments on the nitrogen sources. Sci. Sin. 1975, 18, 659-668.

59. Jefferson, R.A.; Kavanagh, T.A.; Bevan, M.W. Gus fusions- $\beta$-glucuronidase as a sensitive and versatile gene fusion marker in higher-plants. EMBO J. 1987, 6, 3901-3907.

60. Murashige, T.; Skoog, F. A revised medium for rapid growth and bioassays with tobacco tissue cultures. Physiol. Plant 1962, 15, 473-497.

61. Sambrook, J.; Fritch, E.; Maniatis, T.; Russell, D. Molecular Cloning: A Laboratory Manual, 3rd ed.; Cold Spring Harbor Laboratory Press: Long Island, NY, USA, 2001.

62. Boch, J.; Scholze, H.; Schornack, S.; Landgraf, A.; Hahn, S.; Kay, S.; Lahaye, T.; Nickstadt, A.; Bonas, U. Breaking the code of DNA binding specificity of TAL-type III effectors. Science 2009, 326, 1509-1512.

63. Bogdanove, A.J.; Voytas, D.F. Tal effectors: Customizable proteins for DNA targeting. Science 2011, 333, 1843-1846.

64. Li, T.; Liu, B.; Spalding, M.H.; Weeks, D.P.; Yang, B. High-efficiency talen-based gene editing produces disease-resistant rice. Nat. Biotechnol. 2012, 30, 390-392.

65. Moscou, M.J.; Bogdanove, A.J. A simple cipher governs DNA recognition by TAL effectors. Science 2009, 326, 1501.

66. Porteus, M.H. Plant biotechnology: Zinc fingers on target. Nature 2009, 459, 337-338.

67. Townsend, J.A.; Wright, D.A.; Winfrey, R.J.; Fu, F.; Maeder, M.L.; Joung, J.K.; Voytas, D.F. High-frequency modification of plant genes using engineered zinc-finger nucleases. Nature 2009, 459, 442-445.

68. Shukla, V.K.; Doyon, Y.; Miller, J.C.; DeKelver, R.C.; Moehle, E.A.; Worden, S.E.; Mitchell, J.C.; Arnold, N.L.; Gopalan, S.; Meng, X.; et al. Precise genome modification in the crop species zea mays using zinc-finger nucleases. Nature 2009, 459, 437-441.

69. Cai, C.; Doyon, Y.; Ainley, W.; Miller, J.; DeKelver, R.; Moehle, E.; Rock, J.; Lee, Y.-L.; Garrison, R.; Schulenberg, L.; et al. Targeted transgene integration in plant cells using designed zinc finger nucleases. Plant Mol. Biol. 2009, 69, 699-709.

70. McVetty, P.B.E. Cytoplasmic male sterility. In Pollen Biotechnology and Crop Production and Improvement; Shivanna, K.R., Sawhney, V.K., Eds.; Cambridge University Press: Cambridge, UK, 1997; pp. 155-182.

71. Schnable, P.S.; Wise, R.P. The molecular basis of cytoplasmic male sterility and fertility restoration. Trends Plant Sci. 1998, 3, 175-180.

72. Luo, H.; Lyznik, L.A.; Gidoni, D.; Hodges, T.K. Flp-mediated recombination for use in hybrid plant production. Plant J. 2000, 23, 423-430.

73. Perez-Prat, E.; van Lookeren Campagne, M.M. Hybrid seed production and the challenge of propagating male-sterile plants. Trends Plant Sci. 2002, 7, 199-203.

74. Dunwell, J.; Ford, C. Technologies for Biological Containment of GM and non-GM Crops. In DEFRA Contract CPEC 47; The Department for Environment, Food and Rural Affairs (DEFRA): London, UK 2005. Available online: http://www.gmo-safety.eu/pdf/biosafenet/Defra_2005.pdf accessed on 6 June 2012.

75. Dale, P.J. Spread of engineered genes to wild relatives. Plant Physiol. 1992, 100, 13-15. 
76. Eastham, K.; Sweet, J. Genetically Modified Organisms (GMOs): The Significance of Gene Flow through Pollen Transfer; European Environment Agency: Copenhagen, Denmark, 2002; pp.1-74. Available online: http://www.eea.europa.eu/publications/environmental_issue_report _2002_28 (accessed on 6 June 2012).

77. Ellstrand, N.C.; Prentice, H.C.; Hancock, J.F. Gene flow and introgression from domesticated plants into their wild relatives. Ann. Rev. Ecol. Syst. 1999, 30, 539-563.

78. Rogers, H.J.; Parkes, H.C. Transgenic plants and the environment. J. Exp. Bot. 1995, 46, 467-488.

79. Bae, T.W.; Vanjildorj, E.; Song, S.Y.; Nishiguchi, S.; Yang, S.S.; Song, I.J.; Chandrasekhar, T.; Kang, T.W.; Kim, J.I.; Koh, Y.J.; et al. Environmental risk assessment of genetically engineered herbicide-tolerant Zoysia japonica. J. Environ. Qual. 2008, 37, 207-218.

(C) 2012 by the authors; licensee MDPI, Basel, Switzerland. This article is an open access article distributed under the terms and conditions of the Creative Commons Attribution license (http://creativecommons.org/licenses/by/3.0/). 